Resumo de Tese

\title{
Há diferenças na atenção em saúde bucal entre unidades com e sem programa de saúde da família?
}

These Abstract

\section{Are there differences in oral health care between units with and without Family Health Program?}

Alessandra Fabris Valdez

\section{Resumo}

Estudo descritivo sobre a estrutura e processo de trabalho de todas as Unidades Básicas de Saúde de uma cidade da região metropolitana de Porto Alegre (RS), referente à atenção prestada em saúde bucal. Buscou-se identificar o diferencial entre os dois modelos de atenção existentes: Programa de Saúde da Família e tradicional. Para tanto, foi utilizado um questionário semi-estruturado preenchido pelos cirurgiões-dentistas e a média das produções mensais destes profissionais, no período de julho a dezembro de 2004. Os resultados revelaram, entre outros fatores, que ambos os tipos de modelos apresentam problemas quanto ao acesso, estruturação do consultório dentário, limpeza, desinfecção e esterilização de material, porém o tratamento preventivo supera o cirúrgico-restaurador e mutilador. No Programa de Saúde da Família há maior número de atividades extra-unidade, planejamento de ações e reuniões de equipe, enquanto que nas tradicionais a primazia é o trabalho preventivo. Verificou-se que, em idêntico nível de atenção em saúde bucal pública, existem diferenças nas propostas, estratégias e processos de trabalho, contribuindo para tornar heterogênea a organização e o desenvolvimento do atendimento prestado. Assim, concluiu-se que a avaliação das estratégias e a qualificação da atenção básica se faz necessária para a consolidação da saúde bucal coletiva.

Dissertação de Mestrado, 2006. Universidade Luterana Do Brasil - Saúde Coletiva

Disponível em:

http://servicos.capes.gov.br/capesdw/resumo.html?idtese=2006842019010004P0

Palavras-chave:Saúde Bucal; Atenção

Primária; Modelos de Atenção.
Key Words: Oral Health; Primary Care;

Care Models. 